\title{
Sosialisasi Simulasi Ujian Berbasis Komputer Untuk Siswa SMA Negeri 2 Bengkulu Tengah
}

\author{
Khairil, M.Kom*1, Indra Kanedi, M.Kom²,_Shinta Wili Rahayu, M.Si ${ }^{3}$,Fina Nurmita, M.Pd.Mat ${ }^{4}$, \\ Hendri Alamsyah, M.Kom ${ }^{5}$ \\ ${ }^{1}$ Universitas Dehasen, Kota Bengkulu, Indonesia \\ ${ }^{2,3}$ Fakultas Ilmu Komputer Universitas Dehasen Bengkulu, Bengkulu, Indonesia
}

Email: *khairil@unived.ac.id

\begin{abstract}
ABSTRAK
Ujian Nasional merupakan salah satu sistem evaluasi standar pendidikan dasar dan menengah secara nasional dan persamaan mutu tingkat pendidikan antar daerah yang dilakukan oleh Pusat Penilaian Pendidikan. Sistem ujian yang menggunakan media kertas memerlukan dana yang cukup besar untuk pengadaannya, dan juga proses pengiriman yang membutuhkan biaya transportasi dalam pendistribusiannya. Oleh karena itu pada tahun 2014 pemerintah mulai menggunakan sistem ujian nasional berbasis komputer (UNBK). Ujian Nasional Berbasis Komputer (UNBK) disebut juga Computer Based Test (CBT) adalah sistem pelaksanaan ujian nasional dengan menggunakan komputer sebagai media ujiannya. Dengan demikian dilakukan sosialisasi simulasi ujian berbasis computer untuk siswa siswi dan guru pada SMA Negeri 2 Bengkulu Tengah. Sosialiasi ini bertujuan agar dapat meningkatkan kemampuan guru dan siswa dalam pemanfaatan perkembangan IPTEK, serta dapat memberikan pengetahuan kepada siswa dalam menghadapi persiapan UNBK yang sudah berbasis IT.
\end{abstract}

Kata Kunci: UNBK, Computer Based Tes, IPTEK

\section{PENDAHULUAN}

Ujian Nasional merupakan salah satu sistem evaluasi standar pendidikan dasar dan menengah secara nasional dan persamaan mutu tingkat pendidikan antar daerah yang dilakukan oleh Pusat Penilaian Pendidikan, Depdiknas. Berdasarkan Undang-Undang Republik Indonesia nomor 20 tahun 2003 menyatakan bahwa dalam rangka pengendalian mutu pendidikan secara nasional dilakukan evaluasi sebagai bentuk akuntabilitas penyelenggara pendidikan kepada pihak-pihak yang berkepentingan. Untuk mempersiapkan siswa dalam ujian nasional maka sekolah mengadakan beberapa kali test uji coba (tryout) sebelum Ujian Nasional dilaksanakan. Sistem ujian yang menggunakan media kertas memerlukan dana yang cukup besar untuk pengadaannya, belum lagi proses pengiriman yang membutuhkan biaya transportasi untuk pendistribusiannya. Oleh karena itu pada tahun 2014 pemerintah mulai menggunakan sistem ujian nasional berbasis komputer (UNBK). Ujian Nasional Berbasis Komputer (UNBK) disebut juga Computer Based Test (CBT) adalah sistem pelaksanaan ujian nasional dengan menggunakan komputer sebagai media ujiannya. Untuk membiasakan siswa, penyelenggara ujian di setiap sekolah yang melakukan peralihan dari PBT ke CBT maka pemerintah melakukan pengenalan CBT dengan mengadakan Simulasi Ujian Nasional Berbasis Komputer dengan mengganti konsep sebelumnya yang dilakukan pada PBT yaitu try out. Simulasi merupakan suatu teknik meniru operasi-operasi atau proses- proses yang terjadi dalam suatu sistem dengan bantuan perangkat komputer dan dilandasi oleh beberapa asumsi tertentu sehingga sistem tersebut bisa dipelajari secara ilmiah. Ujian bersifat komputer mewajibkan di setiap sekolah harus memiliki perangkat komputer dan perangkat yang mendukung pelaksanaan UNBK, dengan demikian sekolah yang belum memiliki sarana dan prasarana yang baik disekolahnya maka tidak 
(Community Service in the Social, Humanities, Health, Economy and General Areas) Available online at : http://journal.pdmbengkulu.org/index.php/indonesiaraya DOI: https://doi.org/13.11114/bima.1.x.x1-x2

dapat melaksanakan UNBK, menimbang hal tersebut sebaiknya ujian tidak hanya bisa diakses oleh komputer saja. Dengan demikian pelaksanaan UNBK akan lebih merata diadakan di indonesia.

\section{METODE}

Untuk memecahkan masalah yang sudah diidentifikasi dan di rumuskan tersebut diatas, metode kegiatan pelaksanaan pengabdian ini berupa pelatihan dan sosialisasi yang dilakukan untuk siswa dan guru pada SMA Negeri 02 Bengkulu Tengah. Berikut ini adalah tahapan pelatihan dan sosialisasi yang dilakukan:

a. Tahap persiapan

Pada tahap ini dilakukan persiapan meliputi :

1. Persiapan alat dan bahan termasuk program komputer yang berisi materi untuk ujian sebanyak 30 soal.

2. Penentuan waktu pelaksanaan yang tepat.

3. Rapat anggota pengabdian yang diisi dengan diskusi materi dan teknis pelaksanaan pengabdian

b. Tahap Observasi

Tim pengabdian berkonsultasi dengan pihak guru SMA Negeri 2 Bengkulu Tengah berkaitan dengan waktu yang tepat untuk pelaksanaan kegiatan. Tim pengabdian mengamati, mempelajari situasi dan kondisi objek sasaran pengabdian serta beberapa faktor yang mendukung dan menghambat kegiatan, sehingga dapat ditetapkan altematif yang terbaik.

c. Tahap Pelaksanaan

Setelah segala sesuatu dipersiapkan, kelompok pengabdian melaksanakan program kegiatan sesuai dengan rencana kerja yang telah disusun sebelumnya. Tiap anggota kelompok secara bergiliran menyampaikan materi pengabdian sesuai dengan tugas masing-masing.

d. Metode yang digunakan dalam Sosialisasi ini adalah sebagai berikut:

- Ceramahtentang “Simulasi Ujian Berbasis Komputer untuk Siswa SMA Negeri 2 Bengkulu Tengah" dimana penyaji yang beranggotakan 5 orang secara bergantian menjelaskan tentang ujian yang berbasis komputer.

- Pada proses sosialisasi Simulasi Ujian Berbasis Komputer untuk Siswa SMA Negeri 2 Bengkulu Tengah di jelaskan oleh penyaji secara langsung serta memperkenalkan software yang digunakan pada saat uji coba.

Pada sesi Tanya jawab penyaji memberikan kesempatan pada siswa untuk bertanya pada hal-hal yang tidak dimengerti untuk di diskusikan. Selain itu kami sebagai tim juga bertanya tentang hal-hal yang telah dijelaskan. Supaya suasana menjadi bersemangat, ada beberapa doorprize yang sudah disediakan.

\section{HASIL DAN PEMBAHASAN}

A. Evaluasi Keberhasilan

Hasil yang dicapai setelah terlaksananya kegiatan pengabdian ini yaitu:

- Materi yang disampaikan merupakan tambahan pengetahuan bagi siswa kelas 3 untuk bersiap menghadapi ujian nasional yang berbasis komputer.

- Perhatian pihak sekolah untuk mempersiapkan alat-alat pendukung berupa laboratorium yang memadai dengan perlengkapan computer yang sudah tersambung dengan internet.

- Begitu besarnya antusiasme siswa dalam mengikuti ujian ujicoba selama kegiatan berlangsung.

- Penjelasan yang sudah disampaikan oleh kelompok pengabdian telah menambah wawasan peserta pengabdian akan pentingnya pengetahuan perkembangan IT. 
B. Faktor Pendorong dan Pendukung

Keberhasilan pengabdian ini, tidak terlepas dari adanya faktor pendorong dan faktor penghambat, dimana terdapat hal-hal yang dirasakan sebagai faktor penghambat kegiatan ini antara lain waktu yang sesuai untuk melaksanakan pengabdian ini supaya tidak mengganggu jam kegiatan sekolah. Hal ini dapat diatasi berkat kerjasama yang baik antara semua pihak yang terlibat dalam pengabdian ini. Tinggi antusias peserta dalam mengikuti sosialisasi dan kerja sama tim yang baik menjadi factor pendorong terlaksananya pengabdian ini.

\section{KESIMPULAN DAN SARAN}

A. Kesimpulan

Berdasarkan hasil kegiatan dan analisi evaluasi dapat dsimpulkan sebagai berikut:

1. Materi pengabdian sebagai tarnbahan pengetahuan bagi para siswa kelas 3 SMAN 2 Bengkulu Tengah agar belajar dengan baik agar ujian nanti yang sudah berbasis computer berhasil dengan sukses.

2. Peserta pengabdian sangat antusias mengikuti kegiatan, yang dapat meningkatkan B. Saran pengetahuan yang sangat berguna untuk lingkungan sekolahnya.

Sesuai dengan hasil evaluasi respons yang telah dilakukan, kami menyarankan hendaknya program-program pengabdian masyarakat seperti ini bisa dilaksanakan secara reguler dan berkala, melihat tingkat kebutuhan yang sangat tinggi akan pengenalan aplikasiaplikasi komputer yang baru, dalam jangka waktu yang relatif singkat mengikuti perkembangan teknologi secara global.

\section{DAFTAR PUSTAKA}

Budhi Irawan. 2005. Jaringan Komputer. Yogyakarta: Graha Ilmu.

Kumalasari, E. et al (2017). APLIKASI TRYOUT UJIAN ONLINE UNTUKSMA/SMK SEDERAJAT. Jurnal Edukasi, IV(3).

Nurhidayat, Arif. 2016. Implementasi Ujian Nasional Berbasis Komputer atau Computer Based Test (CBT) di SMA Negeri 1 Wonosari. Skripsi. Fakultas Ilmu Pendidikan. Universitas Negeri Yogyakarta. Yogyakarta

Republik Indonesia. 2003. Undang-Undang No. 20 Tahun 2003 tentang Sistem Pendidikan Nasional. Lembaran Negara RI Tahun 1989, No. 6. Sekretariat Negara: Jakarta. 